\title{
Separable Roles of the Nucleus Accumbens Core and Shell in Context- and Cue-Induced Alcohol-Seeking
}

\author{
Nadia Chaudhri*,', Lacey L Sahuque', William W Schairer' and Patricia H Janak', 2,3 \\ 'Ernest Gallo Clinic and Research Center, University of California at San Francisco, Emeryville, CA, USA; '2Department of Neurology, University of \\ California, San Francisco, CA, USA; ${ }^{3}$ Wheeler Center for the Neurobiology of Addiction, University of California at San Francisco, San Francisco, \\ CA, USA
}

\begin{abstract}
Conditioned responding to drug-predictive discrete cues can be strongly modulated by drug-associated contexts. We tested the hypothesis that differential recruitment of the nucleus accumbens (NAc) core and shell mediates responding to drug cues in a drug vs non-drug context. Rats were trained to discriminate between two 10-s auditory stimuli: one stimulus (CS +) was paired with ethanol ( $10 \% \mathrm{v} / \mathrm{v} ; 0.2 \mathrm{ml}$; oral) whereas the other (CS-) was not. Training occurred in operant conditioning chambers distinguished by contextual stimuli, and resulted in increased entries into the ethanol delivery port during the CS + when compared with the CS-. In experiment I, port entries were then extinguished in a second context by withholding ethanol, after which context-induced renewal of ethanol-seeking was tested by presenting both stimuli without ethanol in the previous training context. This manipulation stimulated strong responding to the $\mathrm{CS}+$ in rats pretreated with saline in the core $(n=9)$ or shell $(n=10)$, which was attenuated by pharmacologically inactivating (muscimol/baclofen; $0.1 / 1.0 \mathrm{mM} ; 0.3 \mu \mathrm{l} / \mathrm{side}$ ) either subregion pretest. In experiment 2 , after discrimination, training rats were habituated to a different context in which ethanol and both stimuli were withheld. Cue-induced ethanol-seeking was then elicited by presenting the CS + and CS- without ethanol in the different context. Saline-pretreated rats responded more to the CS + than the CS - (core $n=8$; shell $n=9$ ), and inactivating the core but not shell attenuated this effect. These data highlight an important role for the core in cue-induced ethanol-seeking, and suggest that the shell is required to mediate the influence of contexts on conditioned ethanol-seeking.

Neuropsychopharmacology (2010) 35, 783-79I; doi:I0.1038/npp.2009.187; published online I8 November 2009
\end{abstract}

Keywords: ethanol; renewal; reinstatement; cue reactivity; striatum; addiction

\section{INTRODUCTION}

Relapse to drug addiction in humans can be critically influenced by environmental factors. These include discrete stimuli (cues) that are proximal to the pharmacological effects of a drug, such as the sight, smell, or taste of an alcoholic beverage (McCusker and Brown, 1990; Staiger and White, 1991). Particular configurations of distal stimuli that comprise the physical environment in which drug use regularly occurs (contexts) can also acquire incentive properties through Pavlovian conditioning (Conklin et al, 2008). Subjective and physiological reactivity stimulated independently by drug-associated cues or contexts may facilitate behavior that leads to relapse. Contexts can also modulate conditioned responding to drug-cues, a powerful

\footnotetext{
*Correspondence: Dr N Chaudhri, Ernest Gallo Clinic and Research Center, University of California at San Francisco, 5858 Horton Street Suite 200, Emeryville, CA 94608, USA, Tel: (510) 985-3873, Fax: (510) 985-310।, E-mail: nchaudhri@gallo.ucsf.edu

Received 19 August 2009; revised 26 September 2009; accepted 3 October 2009
}

effect that may provide an additional conduit for relapse (Conklin, 2006).

Animal models of relapse to drug-seeking induced by discrete and discriminative cues are well established (see de Wit and Stewart, 1981; Katner and Weiss, 1999; Shaham et al, 2003; Weiss, 2005 for review). However, behavioral procedures that test the influence of context in drug relapse have emerged more recently (Crombag and Shaham, 2002; Zironi et al, 2006), and only some of these procedures have explicitly analyzed the role of contextual stimuli in modulating drug-seeking behavior that is supported by drug-predictive cues (Crombag et al, 2002; Bossert et al, 2004; Bossert et al, 2006; Tsiang and Janak, 2006). Typically in these studies, instrumental responding that is reinforced with drug delivery and a paired discrete stimulus is acquired in one context and then extinguished in a different context by withholding the drug. Subsequent placement into the previous training context stimulates a renewal of the extinguished response, which continues to produce the discrete stimulus without drug. This model has provided valuable insight into neuronal mechanisms that are operational during context-induced relapse (Crombag et al, 2002; Bossert et al, 2004; Bossert et al, 2006). However, it does not 
enable a precise characterization of the potentially distinct behavioral processes that may regulate renewal, because conditioned responding at test may be controlled by the drug-predictive cue, the environmental context, and/or the modulation of responding to the cue by the context. Thus, an experimentally induced reduction in drug-seeking behavior could reflect impairments in one or more of these operations. Being able to dissociate among these processes is imperative for neuropharmacological research that aims to characterize the neural underpinnings of context-induced relapse to drug-seeking.

One way to define the neural circuits that are required for cue- and context-induced relapse to drug-seeking is to compare the role of particular brain regions in responding to a drug cue that is presented in either a drug-associated context, or a non-drug context. Presenting a cue in a nondrug context should primarily use neural circuits that are important for behavioral responding to the drug cue, whereas additional structures that may be required to process contextual information should be recruited when the cue is encountered in a drug context. This method has been used to show that blocking dopamine D1-family receptors in the nucleus accumbens (NAc) core but not shell reduces instrumental responding for a heroin-predictive cue in a non-heroin context. Conversely, responding for the heroin cue in a heroin-context requires D1-receptor activation in the shell, but not the core (Bossert et al, 2007). These results support an emerging role for the NAc shell in mediating the influence of contexts on behavior (Ito et al, 2008), and substantiate the hypothesis that conditioned responding to discrete drug cues requires the NAc core (Fuchs et al, 2004; Ito et al, 2004; Hollander and Carelli 2007). This study used similar methods to test the hypothesis that Pavlovian conditioned responding to an ethanol-predictive discriminative cue would require the NAc core, and that the renewal of ethanol-seeking triggered by an ethanol context would use the NAc shell.

\section{MATERIALS AND METHODS}

\section{Subjects}

Male, Long Evans rats (Harlan, Indianapolis, IN; $260-280 \mathrm{~g}$ on arrival) were individually housed in ventilated polycarbonate cages in a temperature $\left(21 \pm 1^{\circ} \mathrm{C}\right)$ and lightregulated ( $12 \mathrm{~h}$ light/dark cycle, lights on, $0700 \mathrm{~h}$ ) vivarium. Rats had unrestricted access to rat chow and water. All procedures were approved by the institutional animal care and use committee of the Gallo Center, and concur with recommendations in the Guide for the Care and Use of Laboratory Animals (Institute of Laboratory Animal Resources, Commission of Life Sciences, National Research Council, 1996).

\section{Apparatus}

Conditioning chambers (Med Associates, St Albans, VT) were housed within ventilated sound-attenuating chambers (ambient sound level of $64 \mathrm{~dB}$ ). They comprised clear Plexiglas front and back walls, aluminum side walls, and a stainless steel bar floor beneath which lay a steel pan containing absorbent bedding. The right wall featured a recessed port containing a fluid receptacle into which ethanol (EtOH) was delivered through a 20-ml syringe attached to a pump outside the sound-attenuating cubicle. Head entries into the port were measured by interruptions of a photo beam across its entrance. A white chamber light $(28 \mathrm{~V}$ and $100 \mathrm{~mA})$ was located centrally near the ceiling on the left wall. Chambers were also equipped with a white noise generator $(28 \mathrm{~V}, 10-25 \mathrm{kHz}$, and $80 \mathrm{~dB})$ and a clicker stimulus $(28 \mathrm{~V}, 5 \mathrm{~Hz}$, and $72 \mathrm{~dB})$. Stimulus presentation and fluid delivery were controlled by Med PC IV (Med Associates) software, which also recorded port entries.

\section{Drugs}

EtOH (10\% v/v) was made by combining $95 \%$ EtOH in tap water. The NAc core and shell were pharmacologically inactivated by bilateral microinfusions $(0.3 \mu \mathrm{l} / \mathrm{hemisphere})$ of a drug solution containing muscimol $\left(\mathrm{GABA}_{\mathrm{A}}\right.$ agonist; $0.1 \mathrm{mM}$; Sigma-Aldrich) and baclofen $\left(\mathrm{GABA}_{\mathrm{B}}\right.$ agonist; $1.0 \mathrm{mM}$; Sigma-Aldrich). This muscimol/baclofen (M/B) solution has been shown to selectively influence behavior when infused into the NAc core or shell (Floresco et al, 2006; Fuchs et al, 2004; McFarland and Kalivas, 2001; Chaudhri et al, 2008a). Microinfusions were made through 33-guage injectors attached by polyethylene (PE-50) tubing to $10-\mu$ l Hamilton syringes secured in a Hamilton Syringe pump. The pump was activated for $1 \mathrm{~min}(0.3 \mu \mathrm{l} / \mathrm{min})$. Injectors were left in place for $2 \mathrm{~min}$, after which the rats were returned to their home cages (within the testing room) for 7-9 min, and then placed into the conditioning chambers.

\section{Surgery}

Bilateral, 26-gauge guide cannulae (Plastics One, Roanoke, VA) were implanted using standard stereotaxic procedures, under isoflurane anesthesia. Coordinates for cannula implantation were based on our previous research (Chaudhri et al, 2008a): NAc core, AP +1.2, ML $\pm 2.0, \mathrm{DV}-3.8$; NAc shell, AP +1.6, ML \pm 1.0 , and DV-4.0. Microinfusions used 33 -gauge injectors that protruded $3 \mathrm{~mm}$ below the base of the cannulae (final DV: core, -6.8 ; shell, -7.0 ).

\section{Pre-Exposure to EtOH in the Home Cage}

At 1 week after arrival, rats were acclimated to the taste and pharmacological effects of EtOH by a 24-h access to EtOH and water through two bottles on the home cage for 20 days. To maximize the likelihood that they would attain significant blood EtOH levels, rats were then given limited $\mathrm{EtOH}$ access for $1 \mathrm{~h}$ /day (water, $23 \mathrm{~h}$ /day; 18-28 days). Body weights and liquid volumes were recorded daily. Table 1 provides mean EtOH intakes.

\section{Experiment 1a: Effects of NAc Core or Shell Inactivation on Context-Induced Renewal of EtOH-Seeking}

Pavlovian discrimination training. Rats with cannula targeting the NAc core (final $n=9$ ) and shell (final $n=10$ ) were trained to discriminate between two auditory stimuli over 19, daily 54-minute sessions. Session onset was indicated by illumination of the chamber light. 
Table I Mean ( \pm SEM) Ethanol Intake $(g / k g)$ for the Last 3 Days of I h Access to EtOH During Home Cage Pre-Exposure, and for the Last 2 Days of Initial Pavlovian Discrimination Training (PDT) Sessions

\begin{tabular}{|c|c|c|c|c|}
\hline & \multicolumn{2}{|c|}{ Experiment Ia } & \multicolumn{2}{|c|}{ Experiment 2} \\
\hline & Core $(n=9)$ & Shell $(n=10)$ & Core $(n=8)$ & Shell $(n=9)$ \\
\hline PDT (g/kg) & $0.56 \pm 0.01$ & $0.54 \pm 0.01$ & $0.51 \pm 0.01$ & $0.50 \pm 0.01$ \\
\hline
\end{tabular}

This calculation is based on the weight of the rat, the concentration of ethanol, and the volume consumed.

Rats received 16 random presentations, each of a 10-s white noise or clicker stimulus delivered on separate variable-time 60-s (VT-60) schedules. The onset of one stimulus (CS + ) coincided with EtOH $(0.2 \mathrm{ml}$, delivered into the fluid receptacle over $6 \mathrm{~s}$ ); the second stimulus $(\mathrm{CS}-)$ was presented without EtOH. At the end of each session, ports were checked to ensure that all the EtOH delivered $(3.2 \mathrm{ml})$ had been consumed.

Pavlovian discrimination training (PDT) occurred in one of the two contexts that were distinct across visual, tactile, and olfactory domains. Context 1 had clear Plexiglas chamber walls, a green grid floor, and a strawberry-scented air freshener, which provided a strong visual and olfactory stimulus, taped to the outside of the chamber door. Context 2 had black chamber walls, a smooth Plexiglas floor, and a single spray of acetic acid misted into the bedding beneath the chamber floor. The context used for training, referred to as context A, was kept constant during sessions, and designation of the white noise or clicker as the CS + was counterbalanced across context. Rats were habituated to the microinfusion procedure with a sham infusion using shortened injectors immediately before session 17 .

Extinction. At $24 \mathrm{~h}$ after the final PDT session, rats were placed into the context not used previously (referred to as context B) and exposed to the CS + and CS - as described above, for eight daily sessions. The pump was activated for $6 \mathrm{~s}$ during the $\mathrm{CS}+$ but EtOH delivery was withheld. Before session 2 , rats received a saline microinfusion $(0.3 \mu \mathrm{l})$ to further habituate them to the procedure.

Renewal tests. At $24 \mathrm{~h}$ after the last extinction session, rats were placed into the previous training context (context A) and exposed to the $\mathrm{CS}+$ and $\mathrm{CS}-$ as described above. During the CS + the pump was activated for $6 \mathrm{~s}$ but EtOH delivery was withheld. Before the test, rats received a microinfusion of saline or $\mathrm{M} / \mathrm{B}(0.3 \mu \mathrm{l} / \mathrm{hemisphere} / \mathrm{min})$ according to a within-subject, Latin-square design. Thus, each rat was tested twice, with consecutive tests separated by additional PDT in context A (five sessions) and extinction in context B (six sessions).

\section{Experiment 1b: Effects of NAc Core or Shell Inactivation on PDT}

After the second renewal test, rats from experiment 1a (core, $n=9$; shell, $n=10$ ) were given additional PDT in context $\mathrm{A}$ to examine the role of the core or shell in responding to the $\mathrm{CS}+$ when it was paired with EtOH.
Before session 5 of retraining, they received a microinfusion of either saline or $\mathrm{M} / \mathrm{B}(0.3 \mu \mathrm{l} /$ hemisphere/min $)$, according to a within-subject Latin-square design. Consecutive tests were separated by three sessions of PDT.

\section{Experiment 2: Effects of NAc Core or Shell Inactivation} on Cue-Induced EtOH-Seeking in a Non-EtOH Context

$P D T$. A second cohort of rats with cannula targeting the NAc core (final $n=8$ ) or shell (final $n=9$ ) was trained to discriminate between the CS + and CS- over 19 sessions in context $\mathrm{A}$, as described for experiment 1a. A sham microinfusion was conducted before session 16 .

Habituation to a non-EtOH context. At $24 \mathrm{~h}$ after the last PDT session, rats were placed into context $\mathrm{B}$, where 54-min $\mathrm{EtOH}$, the $\mathrm{CS}+$, and the $\mathrm{CS}-$ were withheld. During these habituation sessions in the non-EtOH context, spontaneous port entries gradually diminished. The pump was activated for $6 \mathrm{~s}$ according to a VT-60 schedule, but EtOH was not delivered. Responding during this 6-s interval did not differ from port entries made during corresponding 6-s intervals when the pump was not activated. Rats received seven habituation sessions in context $\mathrm{B}$, and were habituated to the microinfusion procedure with saline $(0.3 \mu \mathrm{l} /$ hemisphere/ $\min$ ) before session 3 .

Test. At $24 \mathrm{~h}$ after the final habituation session, cue-elicited EtOH-seeking was tested by presenting the CS + and CSwithout $\mathrm{EtOH}$ in the non-EtOH context (context B). Tests were preceded by a microinfusion of either saline or $\mathrm{M} / \mathrm{B}$ $(0.3 \mu \mathrm{l} /$ hemisphere/min) according to a within-subject, Latin-square design. Consecutive tests were separated by PDT (five sessions) in context A and habituation in context B (six sessions).

\section{Statistical Analysis}

Normalized port entries were obtained by subtracting responding during a 10-s pre-CS interval from responding during the corresponding CS. The total number of port entries made during each session was also measured. PDTs for experiments $1 \mathrm{a}$ and 2, and extinction for experiment 1a, were examined using analysis of variance (ANOVA) with session and $\mathrm{CS}(\mathrm{CS}+, \mathrm{CS}-)$ as within-subject repeatedmeasures. Analyses also included the between-subject factors of training context type (context 1 and context 2) and CS + type (white noise and clicker). Any main effects or interactions across these two factors that were present early 
in PDT or extinction were no longer present at the end of PDT or extinction, and did not interact with the test data. Therefore, in the interest of clarity, only the main effects and interactions involving session and CS are presented.

The within-subject design entailed that subjects were retrained and re-extinguished/re-habituated between the two treatments. There were no significant differences in behavior at the end of successive PDT or extinction/ habituation epochs. Data from the last 2 days of successive extinction epochs were averaged to obtain a single baseline for the analysis of renewal in experiment 1a. Renewal tests involved a manipulation of context, as well as a microinfusion that did not also occur during extinction. Therefore, renewal was assessed by comparing extinction and test data from saline-pretreated rats using planned $t$-tests for paired samples (Chaudhri et al, 2008a). The effects of core or shell inactivation were then examined across the within-subject repeated-measures of treatment (saline, M/B) and CS. Similar analyses across treatment were conducted for experiments $1 \mathrm{~b}$ and 2 . Significant main effects and interactions were followed by targeted two-way ANOVAs and $t$-tests for paired or independent samples. One-sample $t$-tests were used to test the hypothesis that difference scores $((C S+$ responding after saline $)-(C S+$ responding after $\mathrm{M} / \mathrm{B})$ ) were different from zero. The criterion for significance was $\alpha=0.05$.

\section{RESULTS}

\section{Experiment 1a. Effect of NAc Core or Shell Inactivation on Context-Induced Renewal of EtoH-Seeking}

Rats with cannula targeting the NAc core were trained to discriminate between a CS + that was paired with $\mathrm{EtOH}$ and a CS - that was not. As observed in Figure 1a, normalized port entries during each CS increased over 19 PDT sessions in context A (session, $\mathrm{F}(18,144)=8.05, \quad p<0.001$ ), with higher response levels developing to the CS + than the CS $-(\mathrm{CS}, \mathrm{F}(1,8)=36.52, p<0.001$; session $\times \mathrm{CS}$, $\mathrm{F}(18,144)=2.62, p<0.01)$. Withholding EtOH during extinction in context B (Figure 1a) caused CS responding across session to decrease (session, $F(7,56)=5.02$, $p<0.001)$. Although responding remained higher during the CS + than the CS $-(\mathrm{CS}, \mathrm{F}(1,8)=45.41, p<0.001)$, the near significant session $\times$ CS interaction $(F(7,56)=2.08$, $p=0.06$ ) suggests a greater reduction in $\mathrm{CS}+$ responding across extinction.

Figure $1 \mathrm{~b}$ depicts baseline responding during extinction in context $\mathrm{B}$, and data from two test sessions in context $\mathrm{A}$ after microinfusion of either saline or $\mathrm{M} / \mathrm{B}$ in the NAc core. After saline pretreatment, placement into the previous training context after extinction in a different context triggered a robust increase in port entries during the $\mathrm{EtOH}-$ predictive CS $+(p<0.01)$, indicative of context-induced renewal of EtOH-seeking. Inactivating the core selectively attenuated the renewal of $\mathrm{CS}+$ responding (treatment, $\mathrm{F}(1,8)=7.59, p<0.05 ; \mathrm{CS}, \mathrm{F}(1,8)=23.92, p<0.01$; treatment $\times$ CS, $\mathrm{F}(1,8)=15.94, p<0.01)$. Compared with saline, CS + responding was reduced after core inactivation $(p<0.01)$, with no change in CS- responding.

Difference scores, calculated by subtracting CS + responding after $\mathrm{M} / \mathrm{B}$ from $\mathrm{CS}+$ responding after saline
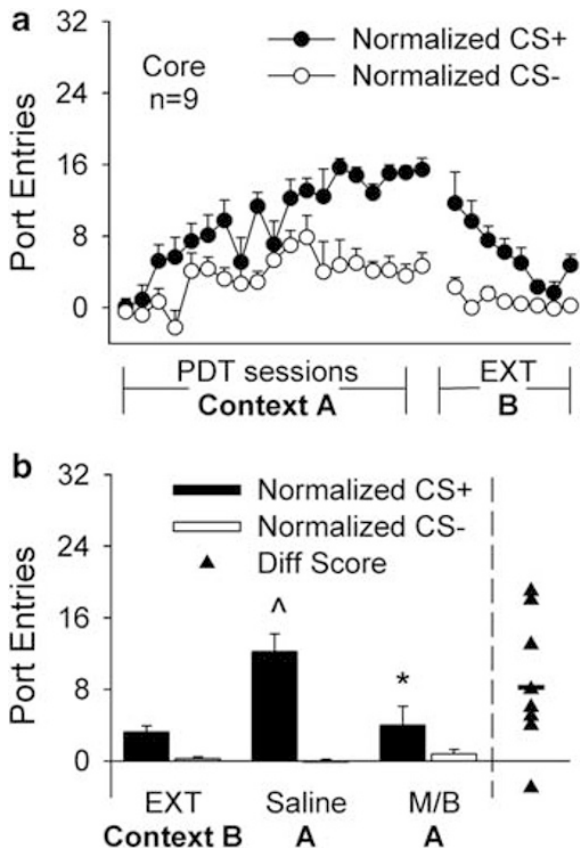

Figure I Inactivating the NAc core reduces context-induced renewal of conditioned responding to an EtOH-predictive CS +. (a) Mean ( \pm SEM) normalized port entries during the CS + (filled symbols) and CS- (open symbols) during 19 Pavlovian discrimination training (PDT) sessions with $10 \% \mathrm{EtOH}$ in context $\mathrm{A}$ and eight extinction (EXT) sessions in context $\mathrm{B}$ in which $\mathrm{EtOH}$ was withheld. (b) Mean $( \pm$ SEM) normalized port entries to the CS + (filled bars) and CS- (open bars) during EXT in context B and at test in context $A$ after saline or $M / B$ infusion. The EXT baseline represents data averaged for the last two sessions of two extinction epochs. Test data are averaged over a single test session. Filled triangles in this and subsequent figures represent difference scores, obtained by subtracting CS + responding after M/B from CS + responding after saline for individual rats. The horizontal line represents the mean difference score. ${ }^{\wedge} p<0.01$ CS + saline vs CS + EXT. * $p<0.01 \mathrm{CS}+$ saline vs CS + M/B.

infusion, indicate that CS + responding was consistently higher after saline compared with M/B pretreatment (triangular symbols - Figure 1b). The mean of the differences score was significantly $>0(t(8)=3.45, p<0.01)$, further confirming that saline-infused rats showed greater context-induced renewal of EtOH-seeking. There was no difference across treatment conditions in the total number of port entries made into the fluid receptacle at test (mean $\pm \mathrm{SEM}$, saline $=17.89 \pm 2.44, \mathrm{M} / \mathrm{B}=16.67 \pm 5.26$; treatment, $\mathrm{F}(1,8)=0.06, p=\mathrm{NS}$ ), indicating a lack of overall motor suppression after core inactivation.

For rats implanted with cannula targeting the NAc shell (Figure 2a), port entries during both stimuli increased across 19 PDT sessions in context A (session, $\mathrm{F}(18,162)=7.00, \quad p<0.001)$, with the development of more rats responding to the $\mathrm{CS}+$ than the CS- (CS, $\mathrm{F}(1,9)=43.15, \quad p<0.001 ; \quad$ session $\times \mathrm{CS}, \quad \mathrm{F}(18,162)=5.36$, $p<0.01)$. CS responding decreased when EtOH was withheld during extinction in context $\mathrm{B}$ (Session, $\mathrm{F}(7,63)=6.88$, $p<0.001)$, with a more pronounced reduction in CS + responding $(\mathrm{CS}, \mathrm{F}(1,9)=34.29, p<0.001$; session $\times \mathrm{CS}$, $\mathrm{F}(7,63)=6.99, p<0.001)$.

Figure $2 \mathrm{~b}$ depicts baseline responding during extinction in context $\mathrm{B}$, and data from two test sessions in context $\mathrm{A}$ after microinfusion with either saline or $\mathrm{M} / \mathrm{B}$ in the NAc 

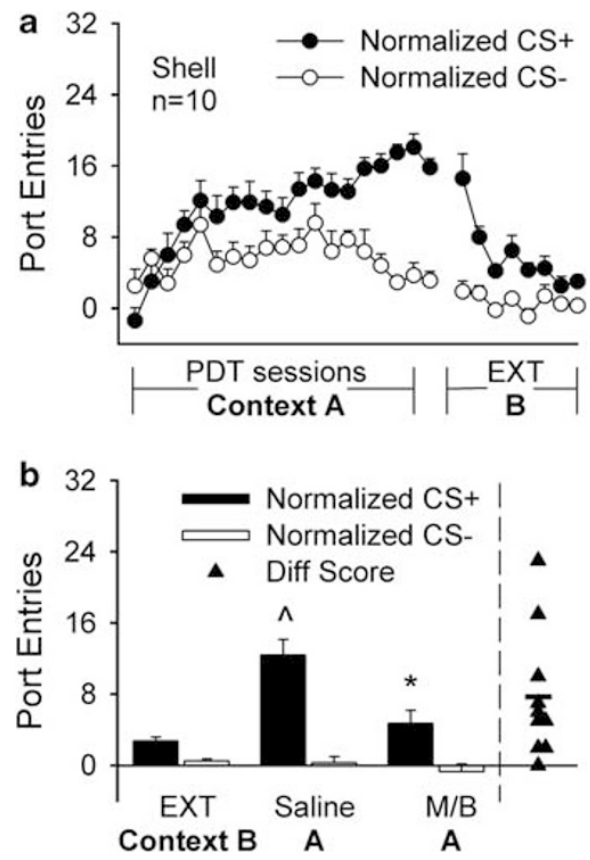

Figure 2 Inactivating the NAc shell reduces context-induced renewal of conditioned responding to an EtOH-predictive CS +. (a) Mean ( \pm SEM) normalized port entries during the CS + (filled symbols) and CS- (open symbols) during 19 PDT sessions with EtOH in context $\mathrm{A}$ and eight EXT sessions in context $B$ in which ethanol was withheld. (b) Mean ( \pm SEM) normalized port entries during the CS + (filled bars) and CS- (open bars) during EXT in context $B$ and at test in context $A$ after saline or $M / B$ infusion. The EXT baseline represents data averaged for the last two sessions of two extinction epochs. Test data are averaged over a single test session. ${ }^{\wedge} p<0.01 \mathrm{CS}+$ saline vs CS + EXT. $* p<0.01 \mathrm{CS}+$ saline vs CS + $\mathrm{M} / \mathrm{B}$.

shell. As was observed with core-implanted rats, placement into the previous training context after extinction in a different context stimulated a selective increase in port entries during the EtOH-predictive $\mathrm{CS}+$ after saline infusion $(p<0.01)$. ANOVA indicated that inactivating the shell reduced context-induced renewal of CS + responding (treatment, $\mathrm{F}(1,9)=12.75, \quad p<0.01 ; \quad \mathrm{CS}, \mathrm{F}(1,9)=45.00$, $p<0.001$; treatment $\times \mathrm{CS}, \mathrm{F}(1,9)=5.79, p<0.05)$. Compared with saline, $\mathrm{CS}+$ responding was significantly reduced after shell inactivation $(p<0.01)$, with no change in $\mathrm{CS}-$ responding.

An examination of difference scores (Figure $2 b$ ) found that the mean was significantly $>0(t(9)=3.38, p<0.01)$, further showing enhanced responding to the EtOHpredictive CS + after saline, compared with shell inactivation. There was no difference across treatment conditions in the total number of port entries made at test (mean \pm $\mathrm{SEM}$, saline $=29.20 \pm 4.96, \mathrm{M} / \mathrm{B}=21.40 \pm 4.40$; treatment, $\mathrm{F}(1,9)=1.88, p=\mathrm{NS})$, indicating no overall motor suppression after inactivation of the shell.

\section{Experiment 1b: Effects of NAc Core or Shell Inactivation on Pavlovian Discrimination}

After their second renewal test, rats from experiment 1a were given additional PDT in context $\mathrm{A}$ to examine the role of the core or shell in responding to the CS + when it was paired with EtOH. Figure 3a depicts normalized CS
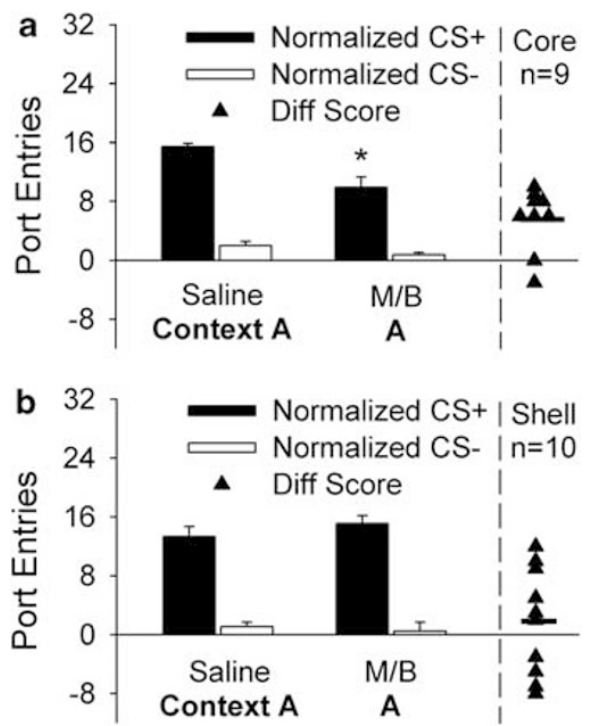

Figure 3 Inactivating the NAc core but not shell attenuates responding to the CS + when it is paired with ethanol. Bars in (a) and (b) depict mean $( \pm$ SEM) normalized port entries to the CS + (filled) and CS- (open) after pre-session saline or M/B infusion during PDT in context $A$ in which the CS + is paired with ethanol. Data are averaged over a single test session. *p $<0.05 \mathrm{CS}+$ saline vs CS + M/B.

responding during PDT after pre-session microinfusion with either saline or $\mathrm{M} / \mathrm{B}$ in the NAc core. ANOVA indicated significant main effects of treatment $(\mathrm{F}(1,8)=19.06$, $p<0.01)$ and CS $(\mathrm{F}(1,8)=182.95, p<0.001)$, as well as a treatment $\times$ CS interaction $(\mathrm{F}(1,8)=7.77, p<0.05)$. Inactivating the core reduced $\mathrm{CS}+$ responding compared with saline $(\mathrm{p}<0.01)$, with no difference in CS- responding.

Difference scores (Figure 3a) provide further indication that CS + responding was higher after saline than after M/B pretreatment, with the mean difference score being significantly $>0(t(8)=3.87, p<0.01)$. However, the total number of port entries made into the fluid receptacle after core inactivation was also significantly reduced compared with saline (mean \pm SEM, saline $=37.56 \pm 2.74 ; \mathrm{M} / \mathrm{B}$ $=28.33 \pm 3.30$; treatment, $\mathrm{F}(1,8)=5.36, p<0.05)$.

Unlike the core, inactivating the NAc shell did not reduce responding to the EtOH-paired CS + during PDT (Figure 3c). ANOVA conducted on test data indicated only a main effect of CS $(F(1,9)=618.23, p<0.001)$. Furthermore, the average of the difference score was not significantly $>0(t(9)=0.78, p=N S)$, indicating that CS + responding after saline was not consistently higher than after shell inactivation (Figure $3 \mathrm{c}$ ). There was also no difference in total port entries across infusion conditions (mean $\pm \mathrm{SEM}$, saline $=62.90 \pm 12.43 ; \mathrm{M} / \mathrm{B}=50.50 \pm 5.34$; treatment, $\mathrm{F}(2,18)=1.50, p=\mathrm{NS})$.

\section{Exp 2: Effects of NAc Core or Shell Inactivation on Cue-Induced EtOH-Seeking in a Non-EtOH Context}

Rats implanted with cannula targeting the NAc core made more port entries during the EtOH-paired CS + than the CS- across 19 PDT sessions in context A (Figure 4a; session, $\mathrm{F}(18,126)=7.45, p<0.001 ; \quad \mathrm{CS}, \mathrm{F}(1,7)=122.37$, $p<0.001$; session $\times \mathrm{CS}, \mathrm{F}(18,128)=4.86, p<0.001)$. 

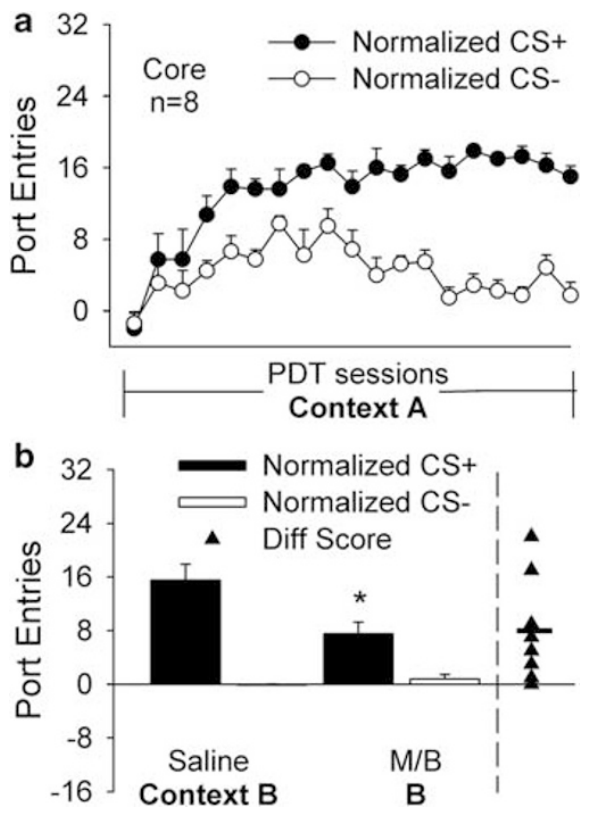

Figure 4 Inactivating the NAc core reduces conditioned responding to an $\mathrm{EtOH}$-predictive cue presented in a context not associated with $\mathrm{EtOH}$. (a) Mean $( \pm$ SEM) normalized port entries during the CS + (filled symbols) and CS- (open symbols) during 19 Pavlovian discrimination training sessions with ethanol in context $A$. (b) Mean ( \pm SEM) normalized port entries to the CS+ (filled bars) and CS- (open bars) after saline or M/B pretreatment at test when the non-extinguished CS + and CS- were presented without $\mathrm{EtOH}$ in context $\mathrm{B}$. Data are averaged over a single test session. $* 0<0.05 C S+$ saline vs $C S+M / B$

Figure $4 \mathrm{~b}$ depicts responding at test in which the CS + and CS- were presented in context B (after seven habituation sessions in context B during which $\mathrm{EtOH}$ and both stimuli were withheld), after an infusion of saline or $\mathrm{M} / \mathrm{B}$ into the NAc core. ANOVA indicated main effects of treatment $(\mathrm{F}(1,7)=7.31, p<0.05)$ and $\mathrm{CS}(\mathrm{F}(1,7)=49.90$, $p<0.001)$ and a significant treatment $\times$ CS interaction $(\mathrm{F}(1,7)=8.34, p<0.05)$. Saline-pretreated rats showed strong discrimination between the non-extinguished, EtOH-predictive $\mathrm{CS}+$, and the CS $-(p<0.01)$; however, core inactivation significantly reduced $\mathrm{CS}+$ responding $(p<0.05)$ with no change in CS - responding.

Analysis of difference scores (Figure $4 \mathrm{~b}$ ) confirmed that rats consistently responded to the $\mathrm{CS}+$ more after saline than after $\mathrm{M} / \mathrm{B}$, with the mean of the difference score being $>0 \quad(t(7)=2.901, p<0.05)$. There were no significant differences in total port entries across the two infusion conditions at test (mean \pm SEM, saline $=20.00 \pm 2.77 ; \mathrm{M} / \mathrm{B}=$ $26.63 \pm 5.55$; treatment, $\mathrm{F}(1,7)=1.08, p=\mathrm{NS}$ ).

Rats implanted with cannula targeting the NAc shell (Figure 5a) made more port entries during the EtOH-paired $\mathrm{CS}+$ than the CS - for 19 PDT sessions in context A (session, $\mathrm{F}(18,144)=8.52, p<0.001 ; \quad \mathrm{CS}, \mathrm{F}(1,8)=55.30$, $p<0.001$; session $\times \mathrm{CS}, \mathrm{F}(18,144)=4.34, p<0.001)$.

In contrast with the core, inactivating the NAc shell did not significantly decrease $\mathrm{CS}+$ responding compared with saline (Figure $5 \mathrm{~b}$ ). ANOVA conducted on test data indicated a main effect of CS $(F(1,8)=26.33, p<0.001)$, but not treatment, and no treatment $\times$ CS interaction. The mean of the differences score was not significantly different from zero $(t(8)=1.04, p=N S)$, indicating that $C S+$ responding
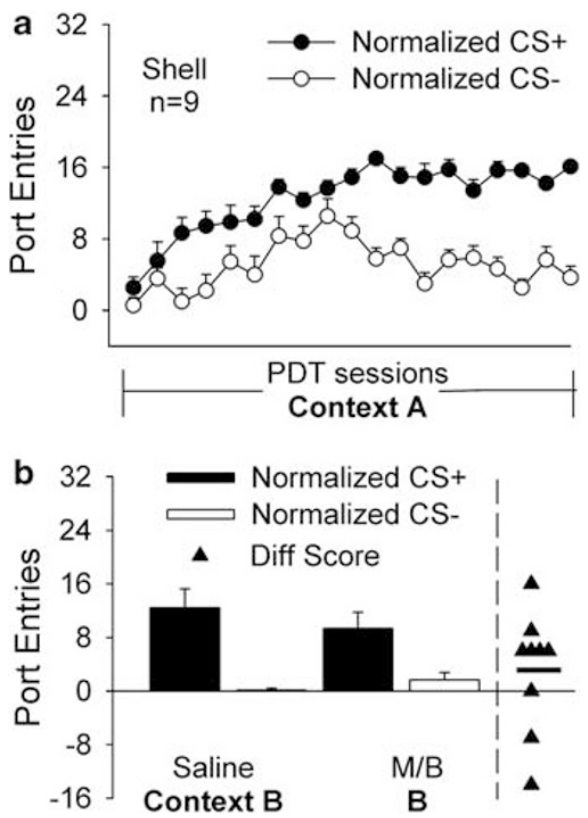

Figure 5 Inactivating the NAc shell does not affect conditioned responding to an $\mathrm{EtO} \mathrm{H}$-predictive cue presented in a context not associated with EtOH. (a) Mean ( \pm SEM) normalized port entries during the CS + (filled symbols) and CS- (open symbols) during 19 Pavlovian discrimination training sessions with ethanol in context $A$. (b) Mean ( \pm SEM) normalized port entries to the CS + (filled bars) and CS- (open bars) after saline or $\mathrm{M} / \mathrm{B}$ infusion at test when the non-extinguished $\mathrm{CS}+$ and $\mathrm{CS}$ - were presented without EtOH in context B. Data are averaged over a single test session.

after saline was not consistently greater than CS + responding after $\mathrm{M} / \mathrm{B}$. There were no differences in total port entries across infusion conditions (mean \pm SEM, saline $=$ $20.44 \pm 5.64 ; \mathrm{M} / \mathrm{B}=29.56 \pm 6.22 ;$ treatment, $\mathrm{F}(1,8)=1.49$, $p=\mathrm{NS})$.

\section{Histology}

Figure 6 illustrates the placement of injector tips in either the NAc core or shell for experiments $1 \mathrm{a}$ and $1 \mathrm{~b}$ (Figure 6a: core $=9$, shell $=10$ ) and experiment 2 (Figure $6 \mathrm{~b}$ : core $=8$, shell $=9$ ). Only rats with cannulae implanted bilaterally into each subregion were included in statistical analyses.

\section{DISCUSSION}

We examined the involvement of the NAc core and shell in conditioned responding to an $\mathrm{EtOH}$-associated cue $(\mathrm{CS}+)$ that was presented in a context linked with previous $\mathrm{EtOH}$ intake, or a context in which EtOH had never been consumed. Placement into an EtOH context after extinction of cue responding in a different context triggered a selective increase in port entries during the $\mathrm{CS}+$, indicative of context-induced renewal of EtOH-seeking. This effect was significantly reduced by inactivating either the NAc core or shell. Conversely, when the non-extinguished CS + and CS - were presented in a non-EtOH context, inactivating the core but not shell selectively reduced responding to the CS + . Inactivating the core but not shell also attenuated responding to the $\mathrm{CS}+$ in a reinforced PDT session. 
a $+2.20$ $+1.70$

$+1.60$

$+1.20$

$+1.00$

$+0.70$

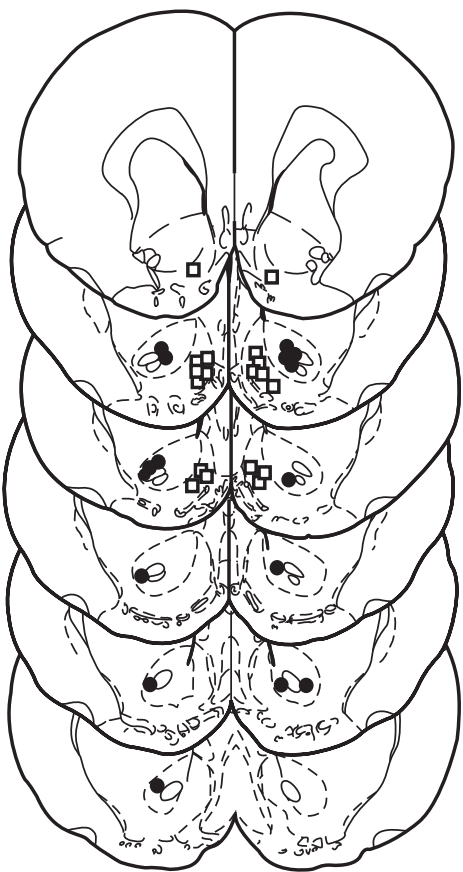

b

$+2.20$
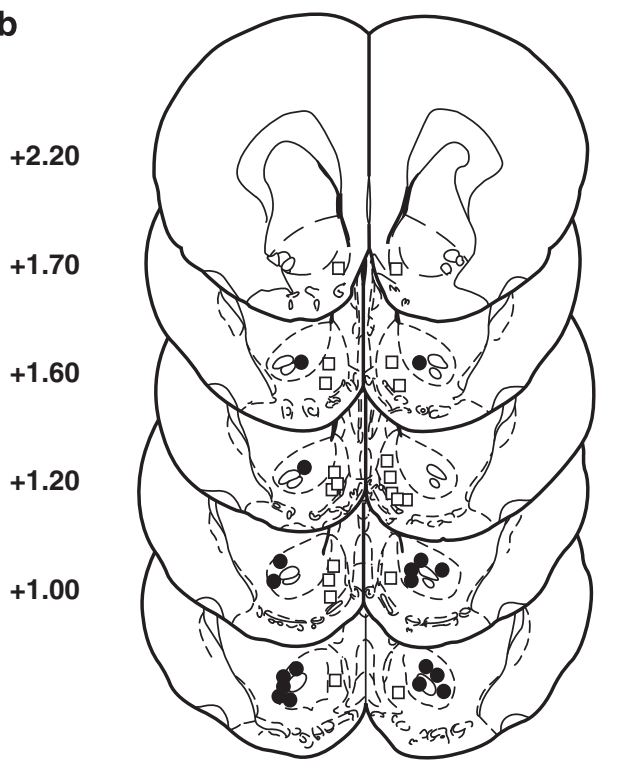

Figure 6 Histological verification of injector tip placements in the NAc core and shell for rats in (a) Experiment Ia and I $\mathrm{b}$ and (b) Experiment 2, according to the rat brain atlas of Paxinos and Watson (1997).

These data support a role for the NAc core in conditioned behavioral responding to discrete EtOH cues, an effect that may be independent of context, and suggest that the shell may mediate the influence of contextual stimuli in renewed EtOH-seeking.

In behavioral animal models of context-induced relapse to drug-seeking, the return to the drug context after extinction in a different context is hypothesized to trigger the recall of conditioned CS-drug associations that were originally formed in that context (see Crombag et al, 2008 for review). The behavioral expression of renewal may therefore be regulated by any combination of processes that include the renewed incentive properties of the drug cue, the excitatory conditioning properties of the context, or the modulation of cue responding by context. The ability to dissociate these processes is critical for studies that aim to characterize the neurobiological mechanisms underlying the specific influence of context in relapse.

To this end, various approaches have been developed to probe the neural circuits that regulate the effects of context in renewed drug-seeking. In one model, the discrete stimulus is omitted entirely and instrumental responding is only reinforced by drug delivery during initial conditioning (eg, Burattini et al, 2006; Fuchs et al, 2005; Zironi et al, 2006). However, this procedure cannot rule out the possibility that salient features in the operant conditioning chamber, such as the operant manipulandum, acquire conditioned incentive properties by virtue of being associated with drug reinforcement. A second approach compares across conditions in which instrumental responding for a drug cue is assessed in either the original training context or in a non-drug context (Tsiang and Janak, 2006; Bossert et al, 2007). In this study we favored the latter method, and modified it to examine the effects of responseindependent presentations of an $\mathrm{EtOH}$-predictive cue on EtOH-seeking behavior, measured as conditioned entries into the fluid port. The inclusion of a CS - served as a within-subject control to gauge the specificity of changes in EtOH-seeking behavior induced by either neuropharmacological or contextual manipulations.

As shown by our laboratory previously, we found that port entries during the CS + and CS- increased in parallel early in PDT (Chaudhri et al, 2008b). Responding to the $\mathrm{CS}+$ then continued to escalate, whereas CS - responding stabilized at a considerably lower level, indicative of behavioral discrimination. Withholding $\mathrm{EtOH}$ during extinction caused port entries during both stimuli to decrease. At test, placement into the previous training context after extinction in a different context elicited increased responding to the EtOH-predictive CS + in saline-pretreated rats, with no change in CS- responding. This result illustrates the selective capacity of the EtOH context to renew extinguished conditioned responding to a discrete EtOHpredictive cue.

Context-induced renewal of EtOH-seeking was significantly attenuated by pretest inactivation of either the NAc core or shell. This finding concurs with studies showing a role for both subregions in context-induced renewal of instrumental cocaine-seeking (Fuchs et al, 2008) and EtOHseeking (Dayas et al, 2007; Chaudhri et al, 2008a). However, there is wide agreement that the NAc core is required for behavioral responding to discrete conditioned cues (Fuchs et al, 2004; Bossert et al, 2007; Ito et al, 2004; Blaiss and Janak, 2009), and emerging evidence that the shell is necessary for utilizing spatial (contextual) information to guide behavior (Bossert et al, 2007; Hamlin et al, 2007; Ito et al, 2008). In this study, the decrease in renewal after core inactivation could therefore be attributed to a reduction in the incentive properties of the CS +, whereas the attenuation in renewal observed after shell inactivation may have resulted from impaired processing of the EtOH context. Evidence from studies of behavioral flexibility (Floresco et al, 2006), Pavlovian conditioned responding to sucrose cues (Blaiss and Janak, 2009), and context-induced renewal of instrumental EtOH-seeking (Chaudhri et al, 2008a) 
suggests that the shell may be particularly important for inhibiting inappropriate behaviors. In this study, however, shell inactivation did not change responding to the CS- (ie, an inappropriate behavior), implying that this region may not serve the same function in discrimination paradigms in which the CS + is reinforced with EtOH.

In support of the hypothesis that the core is required for behavioral responding to the CS +, we found that inactivating the core but not shell before a Pavlovian discrimination session during which the $\mathrm{CS}+$ was paired with $\mathrm{EtOH}$ caused a small but significant reduction in $\mathrm{CS}+$ responding. However, total port entries were also reduced, suggesting the possibility of non-specific effects on behavior. Notably, fluid receptacles were dry at the end of the test session, suggesting that core inactivation did not impair EtOH consumption, but may have dampened the incentive properties of the EtOH-paired CS + .

Stronger evidence that the core mediates conditioned responding to EtOH-predictive cues is provided by the finding that inactivating the core but not shell reduced responding to the non-extinguished $\mathrm{CS}+$ when it was presented in a non-EtOH context (cue-induced EtOHseeking). Hypothetically, this procedure should recruit only neural circuits that are needed for conditioned responding to EtOH cues, which we propose are different (although overlapping) from circuits that are activated when EtOH cues are encountered in an EtOH context. Comparing across studies in which the CS + and CS - are presented in an $\mathrm{EtOH}$ context or a non-EtOH context, it seems that the core is required for conditioned responding to the $\mathrm{CS}+$, regardless of which context it is experienced in. In contrast, the shell was only necessary for the renewal of CS + responding triggered by the EtOH context, supporting a role for this subregion in context-induced relapse to EtOHseeking. Whether this effect is attributable to either the direct excitatory properties of the $\mathrm{EtOH}$ context and/or the modulation of cue responding by the context is unknown.

An intriguing hypothesis suggested by the present data is that the shell may use contextual information to identify the appropriate meaning of the CS + after it has been rendered ambiguous by being paired with $\mathrm{EtOH}$ in one context but not in another. Thus, shell inactivation attenuated renewal, but did not affect CS + responding during PDT or when a non-extinguished $\mathrm{CS}+$ was presented in a non-EtOH context. Renewal tests followed extinction, during which new learning about the relationship between the CS + and the absence of EtOH likely occurred. This new learning may conceivably have recruited the NAc shell, an idea supported by recent evidence that the shell is important for the extinction of instrumental cocaine-seeking (Peters et al, 2008). Therefore, although converging evidence suggests a role for the shell in contextual modulation of conditioned drug-seeking, the precise nature of this role with regard to how it may interact with extinction learning remains a subject for future research.

It is unlikely that the present results are attributable to diffusion of the $M / B$ solution, as the same volume and concentration of $\mathrm{M} / \mathrm{B}$ administered here has been shown to selectively influence behavior in other paradigms (Floresco et al, 2008; Chaudhri et al, 2008a). There were also no differences in total port entries made after pretreatment with saline and $\mathrm{M} / \mathrm{B}$ during context-induced renewal or cue-induced EtOH-seeking tests, suggesting that core or shell inactivation did not cause a generalized locomotor deficit (see also Fuchs et al, 2008).

In summary, the present findings support an important new role for the NAc core in mediating behavioral responding to EtOH-predictive discrete cues, an effect that does not depend on the context in which the cue occurs. This finding provides direction for future research aimed at analyzing neurochemical and cellular mechanisms underlying cue-induced relapse to EtOH-seeking. Our data also support a role for the shell in context-induced relapse to EtOH-seeking, although specific behavioral processes for which the shell is required remain unknown. By using more precise models with which to study the distinct behavioral mechanisms that regulate renewal, future research will be well positioned to define the neural circuits that mediate the effects of discrete cues and environmental contexts, together with their interaction, in relapse to drug-seeking and $\mathrm{EtOH}$ seeking.

\section{ACKNOWLEDGEMENTS}

This research was supported by NIAAA Grant AA014925.

\section{DISCLOSURE}

The authors declare no conflict of interest.

\section{REFERENCES}

Blaiss CA, Janak PH (2009). The nucleus accumbens core and shell are critical for the expression, but not the consolidation, of Pavlovian conditioned approach. Behav Brain Res 200: 22-32.

Bossert JM, Gray SM, Lu L, Shaham Y (2006). Activation of group II metabotropic glutamate receptors in the nucleus accumbens shell attenuates context-induced relapse to heroin seeking. Neuropsychopharmacology 31: 2197-2209.

Bossert JM, Liu SY, Lu L, Shaham Y (2004). A role of ventral tegmental area glutamate in contextual cue-induced relapse to heroin seeking. J Neurosci 24: 10726-10730.

Bossert JM, Poles GC, Wihbey KA, Koya E, Shaham Y (2007). Differential effects of blockade of dopamine D1-family receptors in nucleus accumbens core or shell on reinstatement of heroin seeking induced by contextual and discrete cues. J Neurosci 27: 12655-12663.

Burattini C, Gill TM, Aicardi G, Janak PH (2006). The ethanol selfadministration context as a reinstatement cue: acute effects of naltrexone. Neuroscience 139: 877-887.

Chaudhri N, Sahuque LL, Cone JJ, Janak PH (2008a). Reinstated ethanol-seeking in rats is modulated by environmental context and requires the nucleus accumbens core. Eur J Neurosci 28: 2288-2298.

Chaudhri N, Sahuque LL, Janak PH (2008b). Context-induced relapse of conditioned behavioral responding to ethanol cues in rats. Biol Psychiatry 64: 203-210.

Conklin CA (2006). Environments as cues to smoke: implications for human extinction-based research and treatment. Exp Clin Psychopharmacol 14: 12-19.

Conklin CA, Robin N, Perkins KA, Salkeld RP, McClernon FJ (2008). Proximal versus distal cues to smoke: the effects of environments on smokers' cue-reactivity. Exp Clin Psychopharmacol 16: 207-214. 
Crombag HS, Bossert JM, Koya E, Shaham Y (2008). Review. Context-induced relapse to drug seeking: a review. Philos Trans $R$ Soc Lond B Biol Sci 363: 3233-3243.

Crombag HS, Grimm JW, Shaham Y (2002). Effect of dopamine receptor antagonists on renewal of cocaine seeking by reexposure to drug-associated contextual cues. Neuropsychopharmacology 27: 1006-1015.

Crombag HS, Shaham Y (2002). Renewal of drug seeking by contextual cues after prolonged extinction in rats. Behav Neurosci 116: 169-173.

Dayas CV, Liu X, Simms JA, Weiss F (2007). Distinct patterns of neural activation associated with ethanol seeking: effects of naltrexone. Biol Psychiatry 61: 979-989.

de Wit H, Stewart J (1981). Reinstatement of cocaine-reinforced responding in the rat. Psychopharmacology (Berl) 75: 134-143.

Floresco SB, Ghods-Sharifi S, Vexelman C, Magyar O (2006). Dissociable roles for the nucleus accumbens core and shell in regulating set shifting. J Neurosci 26: 2449-2457.

Floresco SB, McLaughlin RJ, Haluk DM (2008). Opposing roles for the nucleus accumbens core and shell in cue-induced reinstatement of food-seeking behavior. Neuroscience 154: 877-884.

Fuchs RA, Evans KA, Ledford CC, Parker MP, Case JM, Mehta RH et al. (2005). The role of the dorsomedial prefrontal cortex, basolateral amygdala, and dorsal hippocampus in contextual reinstatement of cocaine seeking in rats. Neuropsychopharmacology 30: 296-309.

Fuchs RA, Evans KA, Parker MC, See RE (2004). Differential involvement of the core and shell subregions of the nucleus accumbens in conditioned cue-induced reinstatement of cocaine seeking in rats. Psychopharmacology (Berl) 176: 459-465.

Fuchs RA, Ramirez DR, Bell GH (2008). Nucleus accumbens shell and core involvement in drug context-induced reinstatement of cocaine seeking in rats. Psychopharmacology (Berl) 200: 545-556.

Hamlin AS, Newby J, McNally GP (2007). The neural correlates and role of D1 dopamine receptors in renewal of extinguished alcohol-seeking. Neuroscience 146: 525-536.
Hollander JA, Carelli RM (2007). Cocaine-associated stimuli increase cocaine seeking and activate accumbens core neurons after abstinence. J Neurosci 27: 3535-3539.

Ito R, Robbins TW, Everitt BJ (2004). Differential control over cocaine-seeking behavior by nucleus accumbens core and shell. Nat Neurosci 7: 389-397.

Ito R, Robbins TW, Pennartz CM, Everitt BJ (2008). Functional interaction between the hippocampus and nucleus accumbens shell is necessary for the acquisition of appetitive spatial context conditioning. J Neurosci 28: 6950-6959.

Katner SN, Weiss F (1999). Ethanol-associated olfactory stimuli reinstate ethanol-seeking behavior after extinction and modify extracellular dopamine levels in the nucleus accumbens. Alcohol Clin Exp Res 23: 1751-1760.

McCusker CG, Brown K (1990). Alcohol-predictive cues enhance tolerance to and precipitate 'craving' for alcohol in social drinkers. J Stud Alcohol 51: 494-499.

McFarland K, Kalivas PW (2001). The circuitry mediating cocaineinduced reinstatement of drug-seeking behavior. J Neurosci 21: $8655-8663$

Peters J, LaLumiere RT, Kalivas PW (2008). Infralimbic prefrontal cortex is responsible for inhibiting cocaine seeking in extinguished rats. J Neurosci 28: 6046-6053.

Shaham Y, Shalev U, Lu L, De Wit H, Stewart J (2003). The reinstatement model of drug relapse: history, methodology and major findings. Psychopharmacology (Berl) 168: 3-20.

Staiger PK, White JM (1991). Cue reactivity in alcohol abusers: stimulus specificity and extinction of the responses. Addict Behav 16: 211-221.

Tsiang MT, Janak PH (2006). Alcohol seeking in C57BL/6 mice induced by conditioned cues and contexts in the extinctionreinstatement model. Alcohol 38: 81-88.

Weiss F (2005). Neurobiology of craving, conditioned reward and relapse. Curr Opin Pharmacol 5: 9-19.

Zironi I, Burattini C, Aicardi G, Janak PH (2006). Context is a trigger for relapse to alcohol. Behav Brain Res 167: 150-155. 